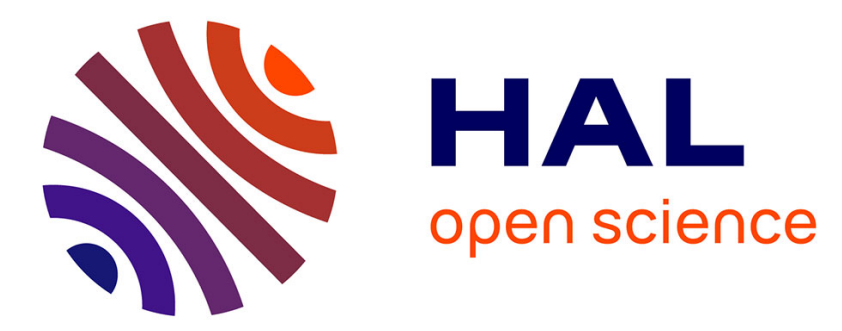

\title{
Urban dynamics of some French cities
}

Denise Pumain, Thérèse Saint-Julien, Lena Sanders

\section{To cite this version:}

Denise Pumain, Thérèse Saint-Julien, Lena Sanders. Urban dynamics of some French cities. European Journal of Operational Research, 1986, 25, pp.3-10. hal-01524103

\section{HAL Id: hal-01524103 \\ https://hal.science/hal-01524103}

Submitted on 17 May 2017

HAL is a multi-disciplinary open access archive for the deposit and dissemination of scientific research documents, whether they are published or not. The documents may come from teaching and research institutions in France or abroad, or from public or private research centers.
L'archive ouverte pluridisciplinaire HAL, est destinée au dépôt et à la diffusion de documents scientifiques de niveau recherche, publiés ou non, émanant des établissements d'enseignement et de recherche français ou étrangers, des laboratoires publics ou privés. 


\title{
Urban dynamics of some French cities
}

\author{
D. PUMAIN, Th. SAINT-JULIEN and L. SANDERS \\ Institut National d'Etudes Démographiques, 27, Rue du Commandeur, 757675 Paris, France
}

\begin{abstract}
Empirical studies of the long-term evolution of the French urban network have showed some regularities which could be interpreted in the framework proposed by the Brussels' school, based on the concepts of 'dissipative structures': evolution according to deterministic trajectories and bifurcations, fluctuations and auto-organization. This empirical research shows the interest of a dynamic spatial model such as the one presented in this paper. The model brings together many well-known empirical regularities and well established theoretical proposals such as logistic growth, economic base theory, distance decay functions, urban ecology and actors' behaviour in an urban context. A first application of this model concerns the evolution of the French agglomeration of Rouen since 1954. The model will be applied to a few French cities in order to estimate the generality of the mechanisms of evolution which are included in the equations. The application shows that there are still some problems, both practical and theoretical, which must be solved before this kind of models will be truly operational. Its principal interest at the moment is theoretical and pedagogical.
\end{abstract}

Keywords: Systems, geography, urban affairs, simulation, differential equations

\section{Introduction}

The territorial patterns of settlements are evolving according to processes, where laws are still not well known. Forecasting has often been frustrated by geographical movements of population, on many different spatial scales: interregional migrations, rural depopulation, or spatial extension of urban areas. With the growing interest for environmental quality and a better awareness of territorial problems in the context of decentralization, it would be desirable to improve our ability to act. We think that testing dynamic spatial models may be a good way to move forward the research in that field: (1) by allowing a test of some existing theoretical proposal; (2) by connecting elementary mechanisms with more global geographical configurations; (3) by providing some tools for forecasting or planning decisions in the future, which are more comprehensive than those which are available today.

We would like to recall here the observations

Received August 1985 which induced us to take some interest in these models, what kind of possibilities they offer, according to our experience, and what problems we met when using them.

\section{Settlement patterns: Open systems far from equilibrium?}

We had first made may empirical studies about the long-term evolution of quantitative aspects of the french urban network (Saint-Julien, 1982, Quant, 1984, Pumain, 1982). The results showed regularities that could be usefully analysed, by analogy, in the interpretative framework proposed by scholars of the Brussels' school (Prigogine and Stengers, 1979).

The main observation is the persistency of the spatial configuration and of the socio-economic differenciations among urban units. This auto-reproduction of the system according to a deterministic trajectory is explained by the great generality of the processes of change (Figure 1). These changes are propagated in the set of cities with a rather high speed: for the period being studied 
(since the beginning of the 19-th century), the demographic or socio-economic transformations have diffused among the cities with a delay of no more than a few years or at most a few decades. Furthermore, this rate of diffusion seems to increase. To the strong constraints set, for example

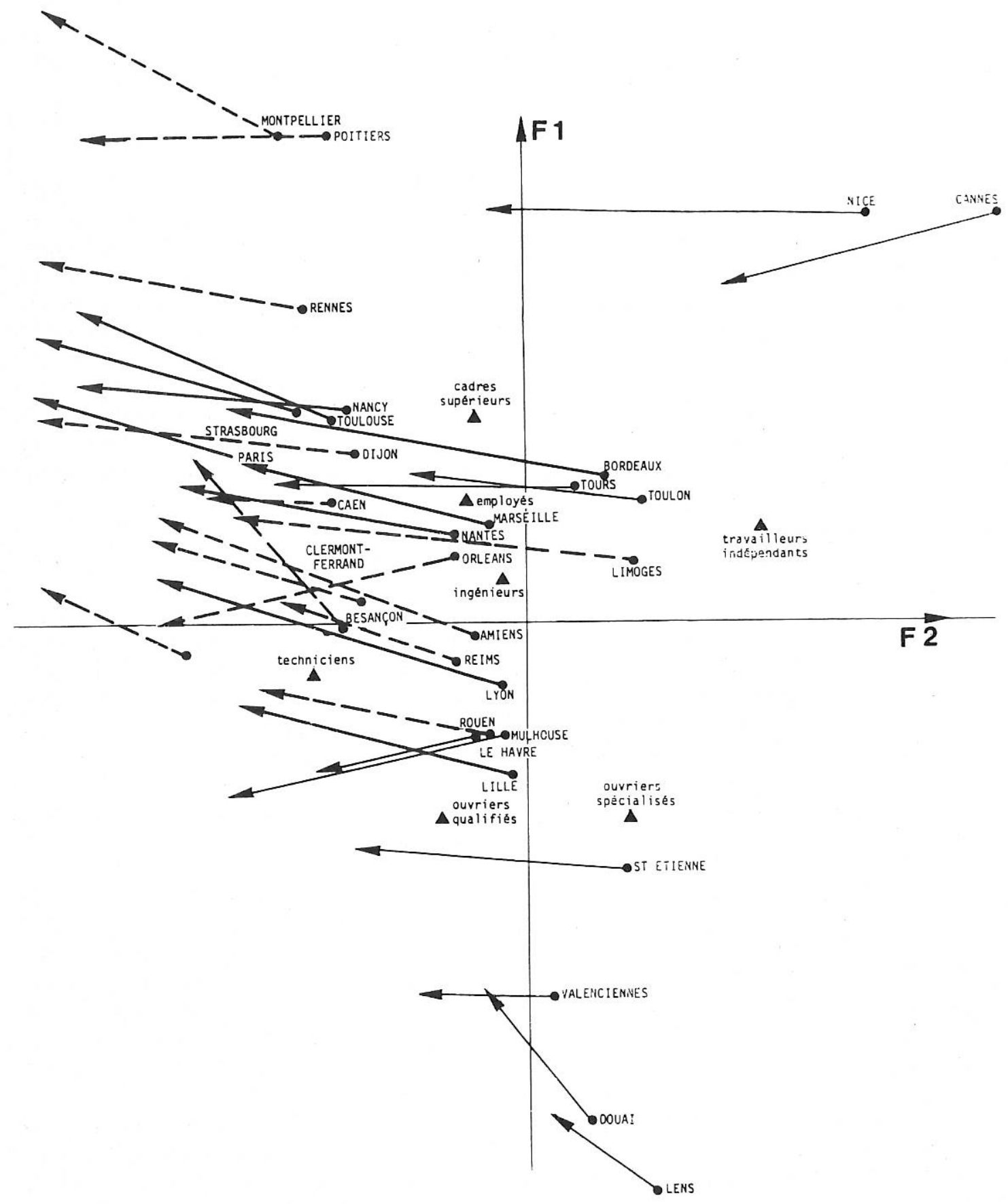

Figure 1. Trajectories of large urban units in the social structure of the French urban system between 1968 and 1975. A Social professional groups. Trajectories of the agglomerations in the social structure:

Paris and "métropoles d'équilibre". - ... "Capitales de région de programme"; $\rightarrow$ Representation of the space of the first two axes from a principal components analysis made on a matrix, which described the social composition (24 categories) of the agglomerations of more than 20000 inhabitants in 1968 for 1968 and 1975 simultaneously. 
by industrial revolution, railway construction, the diffusion of automobile transportation or the final phase of rural depopulation, the urban system

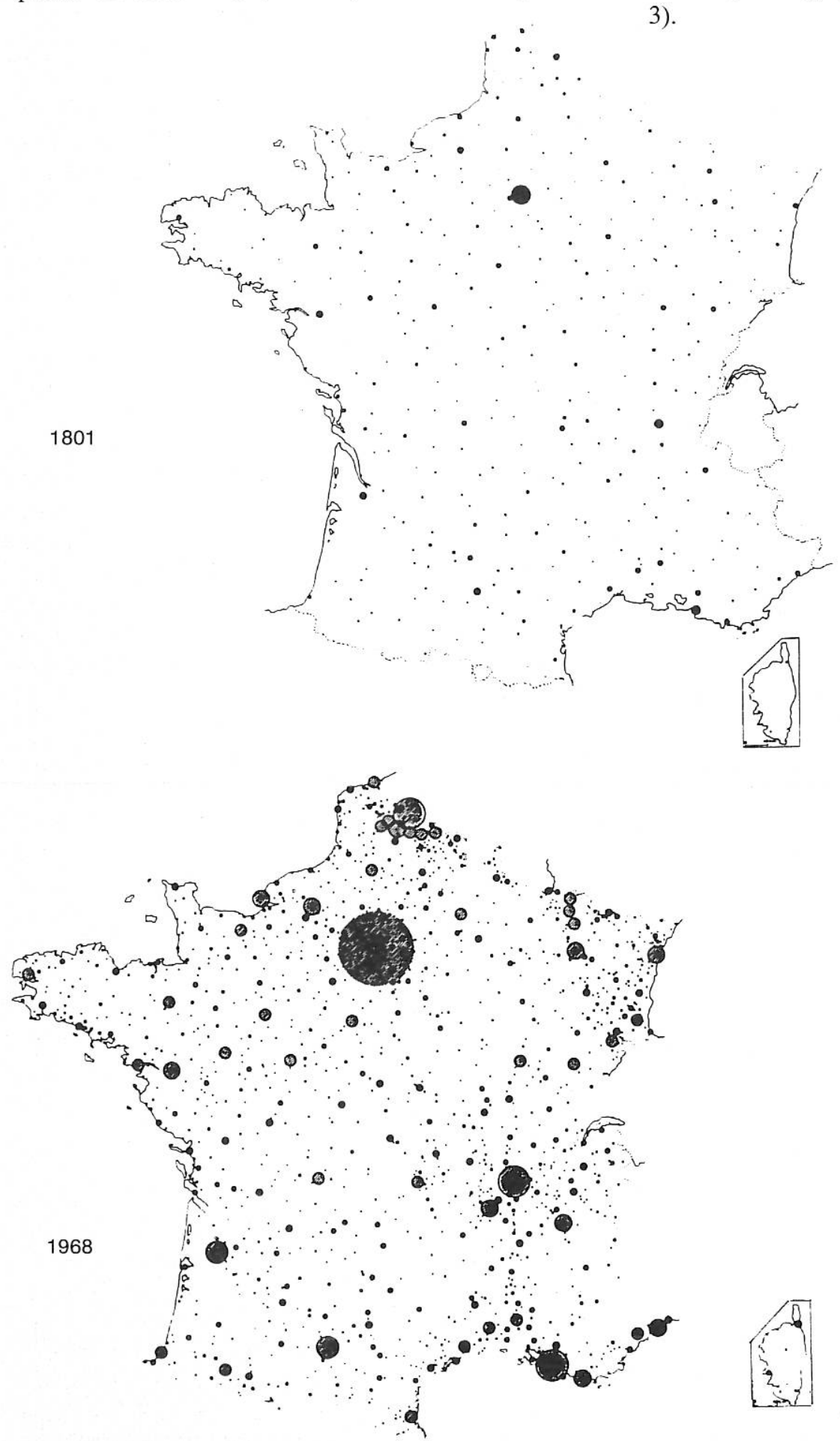

reacted in a way proving the tight interdependency of its elements and its ability to evolve without radically changing its configuration (Figures 2 and 3).

Figure 2. Persistency of the spatial structure of the urban system. (After: Fontanel, C., and Peseux, C., "Potentiel de population et réseau urbain en France", L'Espace Géographique (1976) (4).) 
This adjustment to changing conditions is a permanent process accomplished through numerous fluctuations which do not change the structure of the whole system: instability of growth rates of the population of cities which nevertheless maintain to a great extent their relative position in the hierarchy of sizes, large in- and out-flows of migrants, which do not markedly modify the preexisting differences in urban functions and standards of living of populations according to the cities where they live, the appearance of innovations in a variety of places but whose diffusion tends to conform to the configuration of the system later. It has even been shown (Bussiere, 1982) that a permanent relationship is maintained between the gradient of the size-distribution of towns and the internal density of their populations. This clearly shows an interdependency and the existence of regulations mechanisms between the intra-urban and the interurban systems.

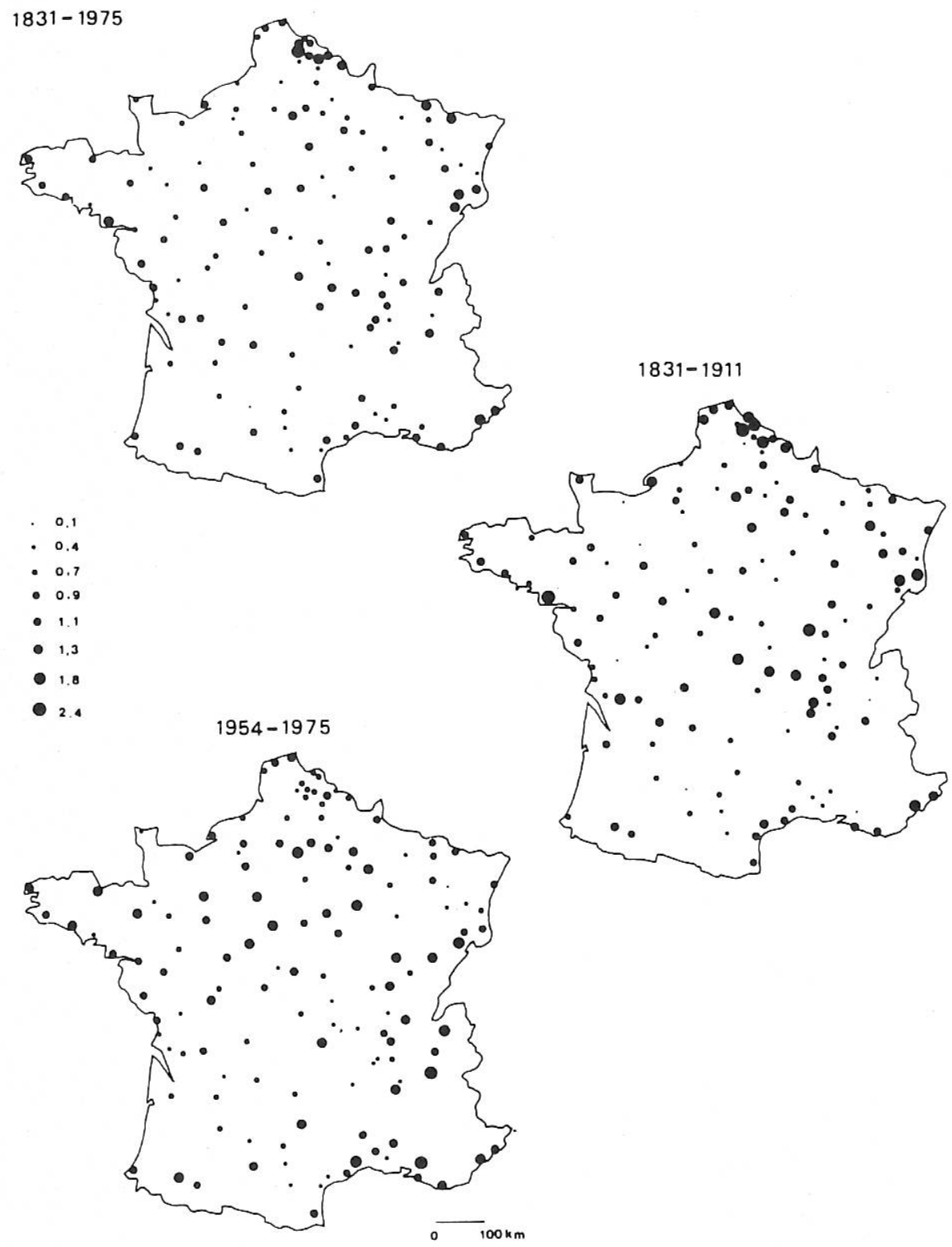

Figure 3. Coefficients of allometric growth 
However, transformations and reorganizations may sometimes occur in the structure of the urban system. It wās shown (Pumain, Saint-Julien, 1979) that they were due to changes of the same kind as those described above, but whose fluctuations ceased to be random with respect to the structure of the system and were, on the contrary, continuously amplified. Such is the case of the reorganization of the French urban network for the benefit of the Parisian, Northern and Eastern regions during the first industrial revolution; and of the growing differentiation over the last thirty years between cities in a central or in a peripheral situation in the urban system. Small quantitative differencies, when accumulated, may create at length a new qualitative dimension in the structure of the system.

Many points of convergence therefore appear between the empirical observations of urban dynamics and the type of evolution which characterizes the 'dissipative structures' that have been studied in chemistry or in biology: a self-organization of the system with periods of predictible evolution according to deterministic trajectories separated by bifurcations, structural modifications which are produced by the amplification of internal fluctuations or external disturbances. Should we stop at this stage of analogy? It seems necessary to go further and to try the mathematical modelling which will test the validity of the proposed formulations.

\section{Beyond the analogy: A spatial dynamic model}

In this exercise we have used the Intra-urban model of Allen (Allen et al., 1981), which simulates the internal evolution of an urban area. Many properties of this model seemed well suited to the study of evolving territorial distributions:

- This model is both dynamic and spatial. The urban area is considered as an open system which is subdivided into many zones and the economic activities and the residential population are distributed among them.

- A large number of the theoretical proposals which were formulated to explain the dynamic of urban space are integrated for the first time in the same model, as mathematical relations or as parameters: multiplier mechanisms of the economic base, spatial interactions according to a gravity-type model, growth upon limited space according to a logistic curve, mechanisms of competition for space and of segregation, unequal speeds of reaction and more or less similarity of behaviours according to the information available to the actors.

- The model assumes that general laws apply to a particular spatial combination, and determines the main part of the observed transformations in the intra-urban distributions of population and activities. The motor of the evolution is given by the difference between existing and potential occupation of each zone. The potential depends on the relative attractivity of this zone upon the whole population and activities, and is

Table 1

Equations of the Intra-urban models

1. Exporting activities

$$
\begin{aligned}
& \frac{\mathrm{d} S^{E}}{\mathrm{~d} t}=\varepsilon^{E} S_{j}^{E}\left(1-\frac{S_{j}^{E}}{D^{E} A_{j} / \sum A_{j}}\right) \\
& \text { with } A_{j}=\left[\frac{\left(1+\rho^{E} S_{j}^{E}\left(1-\psi^{E} S_{j}^{E}\right)\right)}{\mu^{E}+\alpha_{j}^{E} \phi^{E}} \cdot \frac{\tau^{E}}{T^{E}+\sum_{k^{\prime}} x_{j}^{k^{\prime}}+\sum_{l^{\prime}} S_{j}^{l^{\prime}}}\right]^{\mathrm{CO} E} \\
& \begin{array}{l}
S_{j}^{E}=\text { number of employments of activity } E \text { in zone } j \\
E=1=\text { industry } \\
E=2 \text { =xporting tertiary }
\end{array}
\end{aligned}
$$

2. Short-range and medium-range tertiary functions

$$
\begin{aligned}
& \frac{\mathrm{d} S_{j}^{u}}{\mathrm{~d} t}=\varepsilon^{u} S_{j}^{u}\left[1-\frac{S_{j}^{u}}{\sum_{j^{\prime}}\left(\beta^{u} \sum_{k} x_{j}^{k} \frac{A_{j j^{\prime}}}{\sum_{j^{\prime \prime}} A_{j j^{\prime \prime}}^{\prime}}\right)}\right] \\
& \text { with } A_{j j^{\prime}}=\left[\frac{1+\rho^{u} S_{j}^{u}\left(1-\psi^{u} S_{j}^{u}\right)}{\mu^{u}+\phi^{u} \delta_{j j^{\prime}}} \cdot \frac{\tau^{u}}{\tau^{u}+\sum_{k} x_{j}^{k}+\sum_{l^{\prime}} S_{j}^{l^{\prime}}}\right]^{\mathrm{CO}^{u}} \\
& \begin{array}{l}
S_{j}^{u}=\text { number of employments of function } u \text { in zone } j \\
u=3=\text { short-range function (local tertiary) } \\
u=4=\text { medium-range function (regional tertiary) }
\end{array}
\end{aligned}
$$

3. Resident population

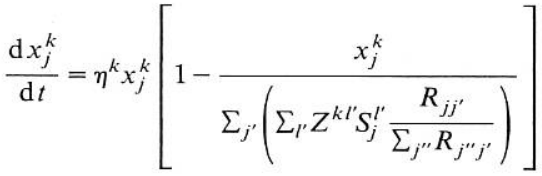

$$
\begin{aligned}
& \text { with } \quad R_{j j^{\prime}}=\left[\frac{\nu^{k}\left(1+\sigma^{k} x_{j}^{k}\right) \mathrm{e}^{-b k} \delta_{j j^{\prime}}}{\nu^{k}+\sum_{k} x_{j}^{k^{\prime}}+\sum_{l^{\prime}} S_{j}^{l^{\prime}}}\right] \\
& x_{j}^{k}=\text { number of residents of category } k \text { in zone } j \\
& k=1=\text { blue collars } \\
& k=2 \text { = white collars } \\
& \delta j j^{\prime}=2 \text { distance between } j \text { and } j^{\prime} \text {. }
\end{aligned}
$$


Table 2

Significance of parameters

\begin{tabular}{|c|c|c|}
\hline Symbol & Significance & $\begin{array}{l}\text { Values in first } \\
\text { simulation }\end{array}$ \\
\hline$\alpha(17,2)$ & $\begin{array}{l}\text { For each zone, accessibility index } \\
\text { to transportation and informa- } \\
\text { tion network }\end{array}$ & 0.1 to 1 \\
\hline$b(2)$ & $\begin{array}{l}\text { Distance-decay parameter for } \\
\text { each resident population cate- } \\
\text { gory }\end{array}$ & $0.5,0.3$ \\
\hline$\beta(2,2)$ & $\begin{array}{l}\text { Induction rate of short range and } \\
\text { medium range tertiary function } \\
\text { by residents of each category }\end{array}$ & $\begin{array}{l}0.5,0.3, \quad 0.5 \\
0.3\end{array}$ \\
\hline $\mathrm{CI}(2)$ & $\begin{array}{l}\text { Elasticity of demand for the cost } \\
\text { of each service }\end{array}$ & 2,2 \\
\hline $\mathrm{CO}(4)$ & $\begin{array}{l}\text { Information available to the ac- } \\
\text { tors }\end{array}$ & $10,10,10,10$ \\
\hline$\varepsilon(4)$ & $\begin{array}{l}\text { Speed of reaction of en- } \\
\text { trepreneurs to the demand }\end{array}$ & $\begin{array}{l}0.001, \quad 0.001 \\
0.01,0.01\end{array}$ \\
\hline$\eta(2)$ & $\begin{array}{l}\text { Speed of adjustment of resident } \\
\text { population to employment offer }\end{array}$ & $0.005,0.005$ \\
\hline$\phi(4)$ & $\begin{array}{l}\text { Transportation cost for each ac- } \\
\text { tivity }\end{array}$ & $\begin{array}{ll}0.02 & 0.0001 \\
0.025 & 0.005\end{array}$ \\
\hline$\mu(4)$ & Production cost for each activity & $1,1,1,1$ \\
\hline$\nu(2)$ & $\begin{array}{l}\text { Sensitivity to crowding for resi- } \\
\text { dents }\end{array}$ & 1000,500 \\
\hline$\rho(4)$ & $\begin{array}{l}\text { Internal cooperativity for each } \\
\text { activity sector }\end{array}$ & $\begin{array}{l}0.01, \quad 0.01 \\
0.0011,0.001\end{array}$ \\
\hline$\psi(4)$ & Density limiting factor & $\begin{array}{lll}0.0, & 0.0, & 0.0 \\
0.0 & \end{array}$ \\
\hline$\sigma(2)$ & $\begin{array}{l}\text { Grouping tendency for a cate- } \\
\text { gory of residents }\end{array}$ & $0.2,0.2$ \\
\hline$\tau(4)$ & $\begin{array}{l}\text { Sensitivity to crowding for each } \\
\text { activity }\end{array}$ & $\begin{array}{l}1000, \quad 3000 \\
1000,2000\end{array}$ \\
\hline$Z(2,4)$ & $\begin{array}{l}\text { Share of each category of resi- } \\
\text { dents working in each activity } \\
\text { sector }\end{array}$ & $\begin{array}{l}1,0.3,0.7,0.5 \\
0.5,0.5\end{array}$ \\
\hline$D(2)$ & External demand & 500,350 \\
\hline
\end{tabular}

constantly revised according to internal and external variations. The actors do not tend to optimize the function or to put the system in equilibria, but adjust it constantly to changing conditions. According to Allen (1981) the non-linearities which tend to structure a town are mainly the product of the imitation and anticipation of the urban actors.

- the mathematical formulation, which generates a dynamics (non-linear differential equations describing the evolution of each activity sector or each population-type on each zone), is designed to allow the simulation of qualitative modifications of the spatial structure of the town, for some values of the parameters associated with particular configurations. When interactions between variables are measured, it is possible to indicate for what value of particular parameters the resulting configuration may become unstable and evolve towards another organisational pattern. It then becomes easier to understand why, among the very large number of possible configurations, only a few of them are frequently observed. It becomes also feasible to see how irreversible situations may be generated, and to explore the universe of possible futures from the starting-point of a given urban story, and to attribute to each of them a probability; (for equations see Tables 1 and 2). However it must be recalled that this kind of urban dynamics is particular to a liberal economy, when supply and demand and a relatively free competition for space are the main rules. The interaction mechanisms of the model are acting unrestrainedly at every point of the urban area being considered (but space may be not homogeneous, or not isotropic, since the accessibility of each zone, which plays an important role in the attractivity, can be measured on a network, and specific constraints for some points of space may be added to the model).

In agreement with Allen and coworkers, we chose to test this model in order to simulate the recent extension of some large french urban agglomerations (Rouen, Nantes, Bordeaux, Strasbourg) (Figures 4 and 5). Then we hope to measure the generality of the mechanisms of evolution contained in the model and to test its pertinence as an operational urban model. To questions like the demographic decline of urban centers, the role of industry in structuring urban space, the residential segregations, or the commuting distances, this model could offer more than a normative answer - a possibility of exploring under various hypothesis the sometimes non-intuitive effects of certain planning devices upon the subsequent configuration of cities. However, before this stage is attained, many problems must still be solved.

\section{Some problems to solve}

One of the main questions is tied to the validity, to the pertinence and the utility of the analogy between the spatial system being considered and the mathematical system of equations used to represent it, and itself being already a representation of observations in the physico-chemical or biological field. This problem has two interrelated 

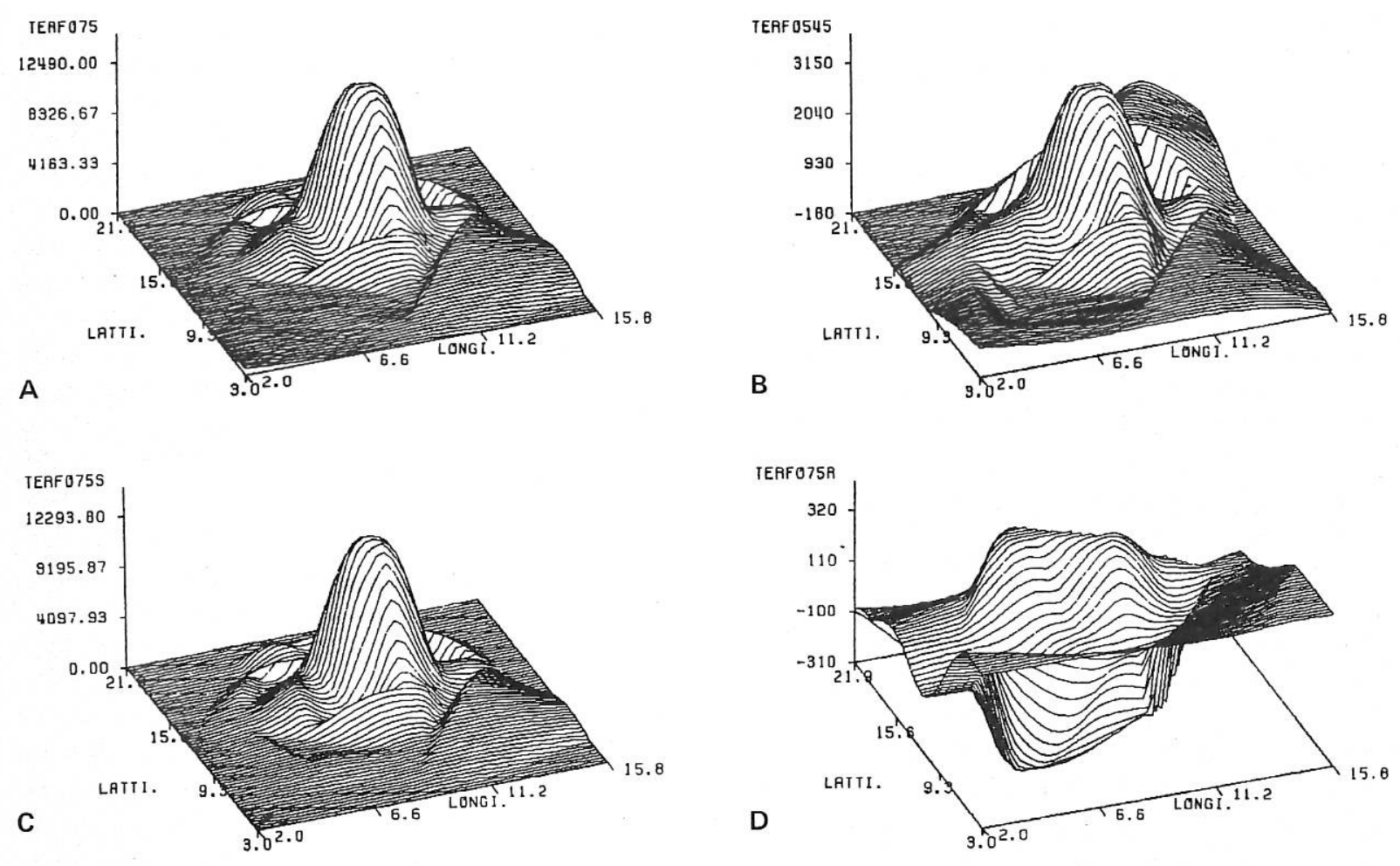

Figure 4. Example of a simulation with Allen's model. Rouen, Intra-urban model, Exporting tertiary 1975. (a) Observed values; (b) evolution; (c) simulation; (d) residuals.
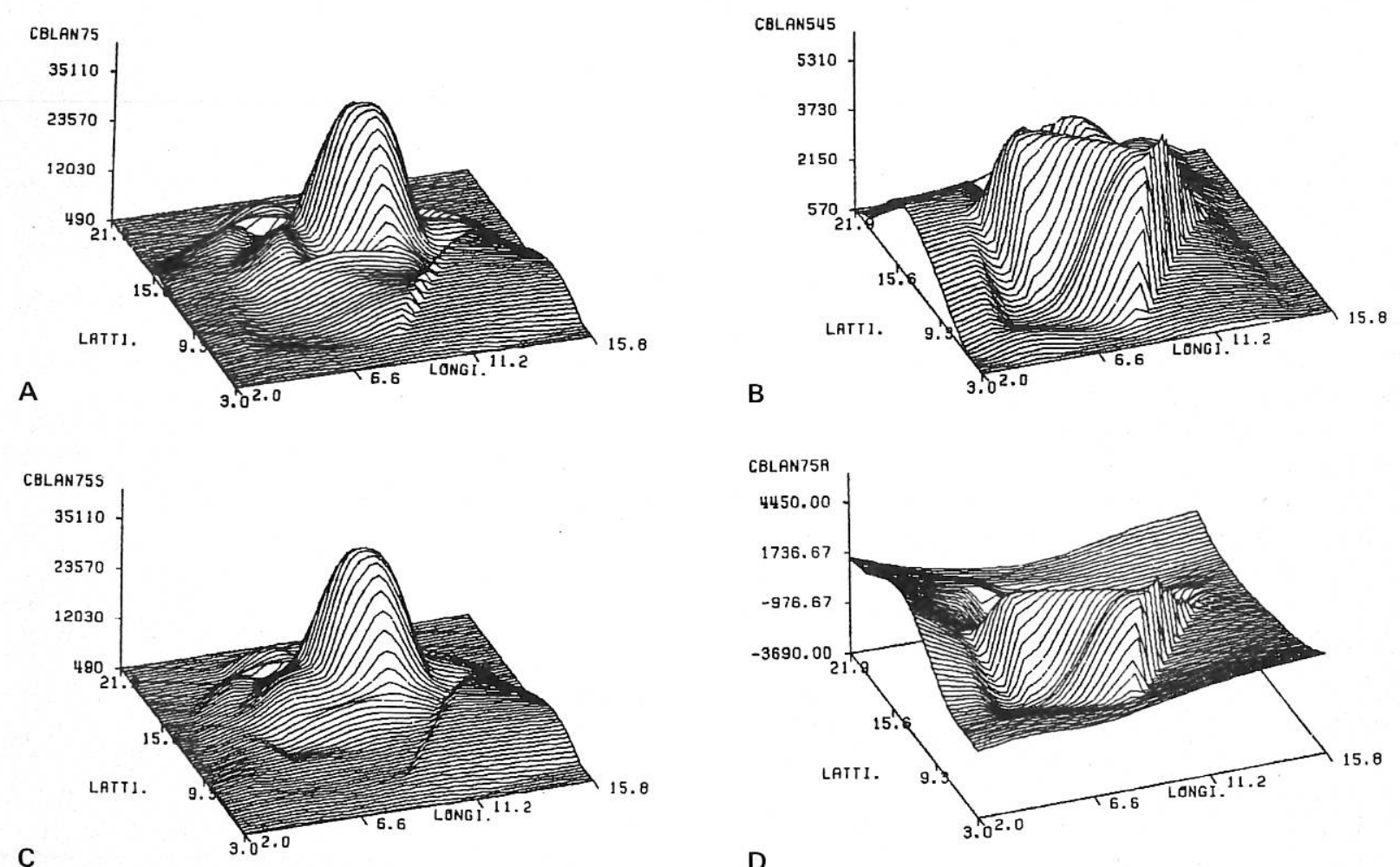

Figure 5. Example of a simulation with Allen's model. Rouen, Intra-urban model, white collars 1954-1975. (a) observed values; (b) evolution; (c) simulation; (d) residuals. 
aspects, one conceptual, the other more practical.

We may pass beyond a simple analogy if a satisfying conceptual identity-from the viewpoint of geographical theory - can be attributed to the variables in the model, to the mathematical relations between them and to the parameters involved in these relations. However, on each of those points, the discussion remains open for the various existing versions of the model. In addition, the discussion is not purely theoretical and rejoins the practical problem: In the actual state of our knowledge in geography, and for a given problem, we cannot strictly ascertain a pertinent choice for variables nor a form for their interactions. Empirical studies of comparative spatial dynamics are also not numerous enough to give the typical values necessary for the parameters of the model. For example, in the case of our application of Allen's model to different cities, we did not find systematic studies with measures for a large number of cases, about the levels of agglomeration economies according to the type of activities, or about the segregative tendencies among social groups, or the differential sensitivity of populations to commuting times or costs. One result of using this type of model may be to invite us to develop a more precise measure of some parameters, whose qualitative importance is often referred to.

Other problems more technical, are however, just as important as they take a decisive place in the effective quality of applications of these models. We must recall the insufficient availability of temporal statistical series for particular localities, at a detailed geographical level and with comparable nomenclature during a long period; we can also recall the classical and inescapable question of the aggregation of spatial data: as parameters and equations refer to individual behaviour, but are applied to persons and activities grouped in a same portion of space; another problem is the necessary discrete formulation of space and time in the equations and in the computation of the model, when mechanisms are supposed to act in a continuous and simultaneous manner-for example, the correspondence between the time in geographical space and the time of the simulations is rather difficult to establish. Moreover, considering the extreme complexity of this kind of models and its high sensitivity to small variations in parameters, the calibrating operations, trying to reproduce by simulation an observed evolution, are always long and difficult.

As a provisional conclusion, we could be tempted to underline more the theoretical and pedagogical utility of this kind of modelisation of spatial dynamics, rather than its operational finality. That comes from the questions which have still to be solved, but also from a general property of the evolution of spatial systems: Most of the time, they are endowed with a great inertia. Bifurcations occur rarely in spatial systems, and most of them imply phenomena of a rather long duration. That is why the main interest of those models, by allowing a study of the qualitative transformations of geographical configurations, seems to us and for the moment to rest in the retrospective interpretation, or in the theoretical exploration of different possible futures, more than a direct and immediate solution of concrete problems. But this is an essential stage for a decisive improvement of knowledge which is necessary for spatial planning.

\section{References}

Allen, P. (1981), "Self-organization in complex systems", Communication au Colloque: Thermodynamique et Sciences de l'Homme, Université de Créteil.

Allen, P., Sanglier, M., Boon, F., Deneubourg, J.L., and de Palma, A. (1981), "Models of urban settlements and structure as dynamic selforganizing systems", Washington DC, Department of Transportation.

Bussière, P. (1982), Systèmes Évolutifs Urbains et Régionaux à l'État d'Équilibre, CRU, Paris.

Prigogine, I., and Stengers, I. (1979), La Nouvelle Alliance, Gallimard, Paris.

Pumain, D. (1982), La dynamique des Villes, Economica, Paris.

Pumain, D., and Saint-Julien, T. (1979), "Les transformations récentes du système urbain Français', L'Espace Géographique 3, 203-210.

Quant, T. (1984), Géoscopie de la France, Minard, Paris.

Reymond, H. (1981), "L'ouverture informatique en géographie urbaine: de l'analyse multivariée socio-économique à la simulation organique des systèmes urbains", Informatique et Sciences Humaines 50, 9-20.

Saint-Julien, T. (1982), Croissance Industrielle et Système Urbain, Economica, Paris. 